\title{
A new evaluation model for fractured horizontal wells in tight reservoirs
}

\author{
Fengzhu Zhang ${ }^{\mathrm{a}^{*}}$,Yuedong Yao ${ }^{\mathrm{b}}$,Xiaocong $\mathrm{Lv}^{\mathrm{c}}$,Weiwei Zhu ${ }^{\mathrm{d}}$ \\ MOE Key Laboratory of Petroleum Engineering in China University of Petroleum, Beijing 102249 \\ àzhangfengzhu0606@163.com, ${ }^{b}$ yaoyuedong@163.com, ${ }^{c} x i a o c o n g l v @ 163 . c o m,{ }^{d}$ jacnil@yeah.net
}

Keywords: evaluation model; response surface method; fractured horizontal well; tight reservoir Abstract: Fractured horizontal wells are widely applied in the development of tight reservoirs nowadays, which will stimulate the seepage zone, reduce resistance near the wellbore and increase productivity. Through analyzing all factors affecting fracturing development effectiveness, select the key factors, and then introduces a series of dimensionless variables to describe reservoir characteristics. All influencing factors with varying values are calculated through a Box-Behnken design. The results are interpreted by a response surface method, and then a quick screening model is obtained to evaluate fractured horizontal wells in tight reservoirs. Sensitivity analysis of single factor and its interaction is carried out based on this model. The research manifests that directing to fractured horizontal wells development in tight reservoirs, this evaluation model and numerical simulation have less error, so it is acceptable to predict the tight reservoirs development and select the optimal development program with this model.

\section{Introduction}

Conventional development measures in tight reservoirs cannot satisfy the productivity requirements, because the small porosity, low permeability and poor connectivity of tight formations. Fracturing technology in horizontal well has been more mature with unremitting efforts of scholars both domestic and oversea. By stimulating sweeping area, it enhances the oil recovery and economical effect. Fracture parameter is the key element to fracturing process and oil recovery is one of the main factors to estimate adaptability of this technology. In order to better estimate the effectiveness, a recovery function of multi-factors need to be build. BBD design can assess the nonlinear relationship between dependent and independent variables. It has fewer trials and will not lead to trials under non ideal condition because BBD does not have axial points. Response surface methodology is a conventional statistic method to optimize influence factors and the regression equation has a high accuracy. It has been widely used in biology, medical fields, however few applications in petroleum industry, so this research introduce RSM as guidance.

\section{Analysis of factors affecting oil recovery}

After constructions of 3-D geological model with typical parameters of tight reservoirs and NWM model to simulate fracture system, then calculate the oil recovery under different parameters. There are many factors affecting recovery:

1) Geological factors: thickness, permeability, porosity, pore throat ratio, crustal stress and maturity of micro-fractures.

2) Fluid factors: oil saturation, oil viscosity, oil density.

3) Engineering factors: well factors and fracture parameters, like location of wells, horizontal length, Fracturing series, length, width, height, aperture of fractures.

Among those factors, crustal stress, thickness of formation, porosity, oil viscosity and density etc. are uncontrollable, while horizontal length, location of wells, fracturing series, half-length, width and flow conductivity of fractures are controllable. Maintain the uncontrollable factors and optimize the controllable factors and calculate its recoveries. Through simulation results, the main factors are length of horizontal well, half-length of fractures, permeability of formation and fracture, fracture 
number. The factors affecting the recovery are shown in Fig. 1.

Introduction of dimensionless groups Based on the above study of main controlling factors for oil recovery, in order to accurately analyze the interaction between factors, reduce the number of affecting factors, and reduce the residual of dimension, dimensionless parameters were selected. According to the dimension analysis, and the relationship between the formation and fracture, five dimensionless were confirmed, including that:dimensionless conductivity $C_{f D}$, the dimensionless half-length of fracture $L_{f D}$, dimensionless length of the horizontal well $L_{D}$, dimensionless fracture spacing $X_{D}$ and number of fractures $N$.

dimensionless conductivity: $C_{f D}=\frac{K_{f} w_{f}}{K L_{f}}$

dimensionless half-length of fracture: $L_{f D}=\frac{L_{f}}{X}$

dimensionless length of the horizontal well: $L_{D}=\frac{L}{Y}$

dimensionless fracture spacing: $X_{D}=\frac{x}{Y}$

number of fractures: $\mathrm{N}$

where $K_{f}$ is the fracture permeability, $10^{-3} \mu \mathrm{m}^{2} ; K$ is the formation permeability, $10^{-3} \mu \mathrm{m}^{2}$; $W_{f}$ is fracture width, $\mathrm{m} ; L_{f}$ is the fracture half length, $\mathrm{m} ; X$ is the length of the reservoir model, $\mathrm{m} ; Y$ is the width of the reservoir model, $\mathrm{m} ; x$ is the fracture spacing, $\mathrm{m} ; L$ is the horizontal well length, $\mathrm{m}$.

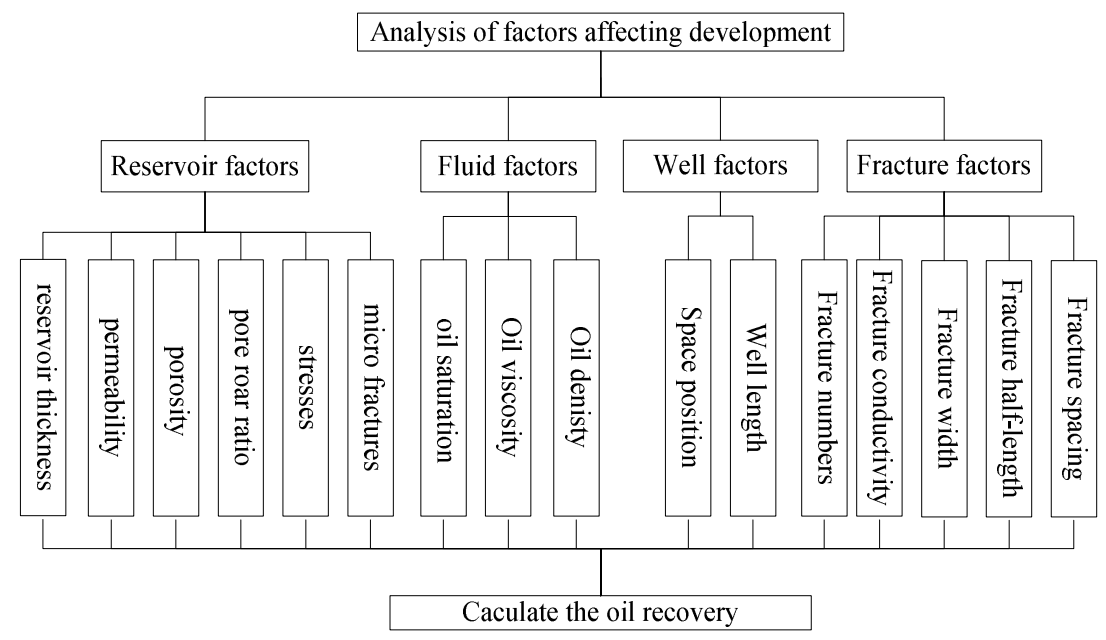

Fig. 1 factors which influence the development of fractured horizontal wells in tight reservoirs

\section{Establishment of evaluation model for oil recovery}

Box-Behnken experimental design Based on a Box-Behnken design for 5 factors and 3 level, we designed 46 experiments. Five dimensionless groups were chosen as independent variables; oil recovery as response values. The criteria of determining range of the dimensionless parameters: The maximum of the positive factors and the minimum of the negative factors were chosen to calculate the high level value of dimensionless groups; the minimum of the positive factors and the maximum of the negative factors were chosen to calculate the low level value of dimensionless groups; the middle value of all factors were chosen to calculate the middle level value of dimensionless groups[1]. All test factors and their ranges are listed in Table 1. 
Table1 Range of dimensionless group values

\begin{tabular}{ccccc}
\hline \multirow{2}{*}{ Factor } & \multirow{2}{*}{ Code } & \multicolumn{3}{c}{ Value } \\
\cline { 3 - 5 } & & Low & Middle & High \\
\hline$C_{\mathscr{D}}$ & $\mathrm{A}$ & 3.00 & 5.00 & 7.00 \\
$X_{D}$ & $\mathrm{~B}$ & 0.08 & 0.09 & 0.10 \\
$L_{D}$ & $\mathrm{C}$ & 0.625 & 0.75 & 0.875 \\
$L_{\mathscr{D}}$ & $\mathrm{D}$ & 0.10 & 0.20 & 0.30 \\
$\mathrm{~N}$ & $\mathrm{E}$ & 4.00 & 6.00 & 8.00 \\
\hline
\end{tabular}

By establishing a three-dimensional geological model and NWM fracture model, then calculate oil recovery of the 46 experiments with Box-Behnken design, the final results listed in Table 2.

Table 2 oil recovery with 46 experiments

\begin{tabular}{ccccccc||ccccccc}
\hline Test & $\mathrm{A}$ & $\mathrm{B}$ & $\mathrm{C}$ & $\mathrm{D}$ & $\mathrm{E}$ & Recovery & Test & $\mathrm{A}$ & $\mathrm{B}$ & $\mathrm{C}$ & $\mathrm{D}$ & $\mathrm{E}$ & Recovery \\
code & $C_{\mathscr{D}}$ & $X_{D}$ & $L_{D}$ & $L_{\mathscr{D}}$ & $\mathrm{N}$ & $R \%$ & Code & $C_{\mathscr{D}}$ & $X_{D}$ & $L_{D}$ & $L_{j D}$ & $\mathrm{~N}$ & $R \%$ \\
\hline 1 & 0 & 1 & 0 & 0 & -1 & 13.46 & 24 & 1 & 0 & -1 & 0 & 0 & 14.19 \\
2 & 0 & 0 & 1 & 0 & 1 & 9.72 & 25 & 0 & 0 & -1 & -1 & 0 & 22.13 \\
3 & 0 & 0 & 1 & 1 & 0 & 13.23 & 26 & -1 & 0 & 0 & -1 & 0 & 22.04 \\
4 & -1 & 0 & 0 & 1 & 0 & 14.98 & 27 & -1 & 0 & 0 & 0 & -1 & 17.88 \\
5 & 0 & 1 & 0 & -1 & 0 & 15.12 & 28 & 0 & 1 & -1 & 0 & 0 & 13.71 \\
6 & 0 & 0 & 1 & 0 & -1 & 10.97 & 29 & 0 & 0 & -1 & 0 & -1 & 14.31 \\
7 & 0 & 0 & 0 & -1 & -1 & 18.76 & 30 & 1 & -1 & 0 & 0 & 0 & 5.11 \\
8 & -1 & -1 & 0 & 0 & 0 & 7.23 & 31 & 0 & 1 & 0 & 0 & 1 & 13.38 \\
9 & 0 & -1 & 0 & -1 & 0 & 15.13 & 32 & 0 & 0 & 0 & 1 & -1 & 12.88 \\
10 & 0 & 0 & 0 & 1 & 1 & 10.56 & 33 & 1 & 0 & 0 & 0 & 1 & 13.64 \\
11 & 1 & 0 & 0 & -1 & 0 & 17.79 & 34 & 0 & -1 & 0 & 0 & -1 & 6.1 \\
12 & 0 & 0 & -1 & 0 & 1 & 10.1 & 35 & 0 & 1 & 1 & 0 & 0 & 13.82 \\
13 & 0 & -1 & -1 & 0 & 0 & 9.98 & 36 & 0 & -1 & 1 & 0 & 0 & 5.08 \\
14 & 0 & 0 & -1 & 1 & 0 & 15.29 & 37 & 1 & 0 & 0 & 0 & -1 & 13.93 \\
15 & 1 & 0 & 0 & 1 & 0 & 13.65 & 38 & 0 & 1 & 0 & 1 & 0 & 14.5 \\
16 & 0 & 0 & 0 & 0 & 0 & 13.73 & 39 & -1 & 0 & 1 & 0 & 0 & 13.86 \\
17 & 0 & 0 & 0 & 0 & 0 & 13.73 & 40 & 0 & 0 & 0 & 0 & 0 & 13.73 \\
18 & 0 & 0 & 0 & 0 & 0 & 13.73 & 41 & -1 & 0 & 0 & 0 & 1 & 13.45 \\
19 & 0 & -1 & 0 & 1 & 0 & 5.39 & 42 & -1 & 1 & 0 & 0 & 0 & 13.6 \\
20 & 0 & 0 & 0 & 0 & 0 & 13.73 & 43 & -1 & 0 & -1 & 0 & 0 & 14 \\
21 & 1 & 0 & 1 & 0 & 0 & 14.12 & 44 & 1 & 1 & 0 & 0 & 0 & 13.37 \\
22 & 0 & 0 & 0 & -1 & 1 & 21.74 & 45 & 0 & 0 & 0 & 0 & 0 & 13.73 \\
23 & 0 & -1 & 0 & 0 & 1 & 4.99 & 46 & 0 & 0 & 1 & -1 & 0 & 15.42 \\
\hline & & & & & & & & & & & & &
\end{tabular}

\section{Result analysis of trial design}

Dependability analysis of equation RSM can obtain a regression equation charactering the relationship between dependent and independent variables, and build a Multidimensional surface close to actual condition. However, it has many RSM models, so it is necessary to sift the fitting models in RSM. According to the results shown in Table 3, quadratic polynomial model is better than any other models based on mean square error and test results in variance analysis, so adopt this model in preference. The comparison results of multiple correlation coefficients, mean square error and sum of square partial variance shown in Table.4, indicate that quadratic polynomial model is optimal. Adjusted determination coefficient of recovery regression equation $\mathrm{R}^{2}$ is 0.92 and the multiple correlation coefficients $\mathrm{R}$ is 0.959 , which means the prediction values of recovery fit well with actual values and this model has a small trial error, so it can be used to analyze and predict the influence that fractures bring to recovery. The quadratic polynomial model of recovery is shown in Eq 1.

$$
\begin{aligned}
& \mathrm{R}_{1}=-147.37-6.54 C_{f D}+5606.19 X_{D^{-}}-98.81 L_{D^{-}} 396.82 L_{f D^{-}} 1.52 N+23.63 C_{f D} X_{D}+0.07 C_{f D} L_{D}+3.65 \\
& C_{f D} L_{f D}+026 C_{f D} N+1002 X_{D} L_{D}+2280 X_{D} L_{f D^{+}}+12.87 X_{D} N+93 L_{D} L_{f D}+2.96 L_{D} N-6.62 L_{f D} N+0.17 C_{f D^{2}} \\
& 37135.41 X_{D^{2}-24.54 L_{D}+283.98 L_{f D^{2}}-0.18 \mathrm{~N}^{2}}
\end{aligned}
$$


Table 3 Dependability analysis of different recovery models

\begin{tabular}{ccccccc}
\hline Source & $\begin{array}{c}\text { sum } \\
\text { Square }\end{array}$ & $\begin{array}{c}\text { Degree of } \\
\text { freedom }\end{array}$ & $\begin{array}{c}\text { Mean } \\
\text { square }\end{array}$ & Fvalue & $\begin{array}{c}\text { Probability } \\
(\mathrm{P})>\mathrm{F}\end{array}$ & Remark \\
\hline Mean vs Total & 8115.41 & 1 & 8115.41 & & & \\
Linear vs Mean & 344.77 & 5 & 68.95 & 7.28 & $<0.0001$ & \\
2FI vs Linear & 49.26 & 10 & 4.93 & 0.45 & 0.9095 & \\
Quadratic vs 2FI & 273.44 & 5 & 54.69 & 24.32 & $<0.0001$ & Suggested \\
Cubicvs Quadratic & 36.34 & 15 & 2.42 & 1.22 & 0.3837 & \\
Residual & 19.86 & 10 & 1.99 & & & \\
Total & 8839.08 & 46 & 192.15 & & & \\
\hline
\end{tabular}

Table 4 Synthetical analysis of $\mathrm{R}^{2}$ on different recovery models

\begin{tabular}{ccccccc}
\hline Type & $\begin{array}{c}\text { Standard } \\
\text { deviation }\end{array}$ & $\mathrm{R}^{2}$ & $\begin{array}{c}\text { Adjusted } \\
\mathrm{R}^{2}\end{array}$ & $\begin{array}{c}\text { Predicted } \\
\mathrm{R}^{2}\end{array}$ & PRESS & Remark \\
\hline Linear vs Mean & 3.08 & 0.48 & 0.41 & 0.28 & 520.04 & \\
2FI vs Linear & 3.32 & 0.54 & 0.32 & 0.25 & 903.76 & \\
Quadratic vs 2FI & 1.50 & 0.95 & 0.92 & 0.91 & 224.83 & Suggested \\
Cubicvs Quadratic & 1.41 & 0.97 & 0.88 & 0.76 & 1271.25 & \\
\hline
\end{tabular}

Significance analysis of parameters The value of $\mathrm{F}$ can be used to test every parameters significance of influencing the response value, the smaller value $p$ has, the higher significance degree of corresponding parameter has. Generally, if $p<0.05$, parameters significance degree is quite high; if $0.05<\mathrm{p}<0.1$, the degree is high. According to the results shown in Table 5, five dimensionless parameters all have a high significance to recovery. Dimensionless fracture space $X_{D}$ has a more significant interaction with dimensionless fracture half-length $L_{f D}$; fracture number $N$ has a significant interaction with dimensionless half-length $L_{f D} ; X_{D}^{2}, L_{f D}{ }^{2}$ have a significant surface effect to respond value. In order to have a quick assessment of target reservoir, a quadric multiple regression equation can be obtained after fitting the equation with a simplified model and deletion of insignificant items $(\mathrm{p}>0.1)$. The Simplified model is shown in Eq 2.

$$
\begin{aligned}
& \mathrm{R}_{2}=-147.37-6.54 C_{f D}+5606.19 X_{D^{-}}-98.81 L_{D^{-}} 396.82 L_{f D^{-}}-1.52 N+2280 X_{D} L_{f D^{-}} 6.62 L_{f D} N+37135.41 \\
& X_{D^{2}+283.98 L_{f D^{2}}}
\end{aligned}
$$


Table 5 quadratic polynomial model and variance analysis of its parameters

\begin{tabular}{cccc}
\hline Sourse & Mean square & $\mathrm{F}$ value & P value \\
\hline Model & 667.47 & 14.84 & $<0.0001$ \\
$\mathrm{~A}-C_{f D}$ & 7.90 & 3.51 & 0.0427 \\
$\mathrm{~B}-X_{D}$ & 168.68 & 75.02 & $<0.0001$ \\
$\mathrm{C}-I_{D}$ & 19.12 & 8.50 & 0.0074 \\
$\mathrm{D}-I_{f D}$ & 141.91 & 63.12 & $<0.0001$ \\
$\mathrm{E}-N$ & 7.17 & 3.19 & 0.0863 \\
$\mathrm{AB}$ & 0.89 & 0.40 & 0.5343 \\
$\mathrm{AC}$ & 0.0012 & 0.0054 & 0.9816 \\
$\mathrm{AD}$ & 2.13 & 0.95 & 0.3395 \\
$\mathrm{AE}$ & 4.28 & 1.91 & 0.1796 \\
$\mathrm{BC}$ & 6.28 & 2.79 & 0.1073 \\
$\mathrm{BD}$ & 20.79 & 9.25 & 0.0055 \\
$\mathrm{BE}$ & 0.27 & 0.12 & 0.7341 \\
$\mathrm{CD}$ & 5.41 & 2.40 & 0.1336 \\
$\mathrm{CE}$ & 2.19 & 0.97 & 0.3331 \\
$\mathrm{DE}$ & 7.02 & 3.12 & 0.0894 \\
$\mathrm{~A}^{2}$ & 4.18 & 1.86 & 0.1847 \\
$\mathrm{~B}^{2}$ & 120.35 & 53.53 & $<0.0001$ \\
$\mathrm{C}^{2}$ & 1.28 & 0.57 & 0.4569 \\
$\mathrm{D}^{2}$ & 70.38 & 31.30 & $<0.0001$ \\
$\mathrm{E}^{2}$ & 4.55 & 2.02 & 0.1673 \\
\hline & & &
\end{tabular}

The analysis of recovery response surface The conclusion can be drew from significance analysis: dimensionless fracture space $X_{D}$ has a more significant interaction with dimensionless half-length of fracture $L_{f D}$; dimensionless half-length $L_{f D}$ has a significant interaction with fracture number $N$. For better direct analysis, the recovery response surface and its contour line are shown in Fig.2.

From the contour lines figures of $X_{D}$ vs $L_{f D}$, when the half-length of fracture is determined, with the increase of fracture space, the recovery increases at first and remain unchanged later. At the beginning, the interferes between fractures reduce with the increase of fracture space, however the influence declines with the further increase of space and finally the recovery remains unchanged.

From the respond surface figures of $L_{f D}$ vs $N$, when the half-length is determined, with the fracture number increases, the recovery increase at first and decreases later. The fractures functions as main seepage channel at the beginning and enhance the recovery, however with more fractures, the interferes become serious and make the recovery decline .
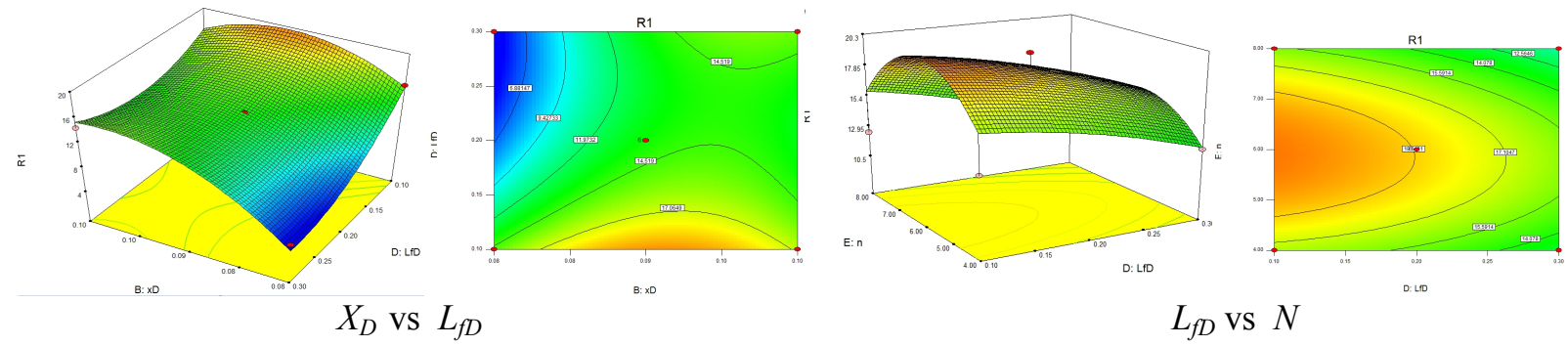

Fig. 2 respond surface(left) and contour lines(right) of fracture parameters

\section{Conclusion}

After analyzing the factors influencing the oil recovery, we introduced five dimensionless groups to characterize the reservoir. Based on the Box-Behnken design, all factors with varying values affecting recovery were calculated, the results were interpreted by the response surface method, and a evaluation model for evaluating fractured horizontal wells in tight reservoirs was obtained finally. The main understandings are shown as follows:

1) There are many factors influencing the recovery, the most influencing factors are length of horizontal well, half-length of fractures, permeability of formation and fracture, fracture number.

2) Based on analysis of main factors influencing the recovery, the affiliation relation between every factor was determined by dimension analysis and the theory of physics. Five dimensionless 
groups were selected (such as dimensionless conductivity $C_{f D}$, the dimensionless half-length of fracture $L_{f D}$, dimensionless length of the horizontal well $L_{D}$, dimensionless fracture spacing $X_{D}$ and number of fractures $N$ ) and the five dimensionless groups were able to character reservoir properties.

3) The evaluation model established through the Box-Behnken design and response surface method. It can be used to quickly evaluate the oil recovery for the development of tight oil reservoirs in China.

4) Based on sensitivity analysis and test of the evaluation model, the factors are listed in order of importance as follows: fracture spacing, half-length of fracture, horizontal well length, fracture conductivity, fracture number.

\section{Reference}

[1] Yao Y D and Ji Zemin. A quick evaluation model for $\mathrm{CO}_{2}$ flooding and sequestration. Pet.Sci.(2010)7:515-523.

[2] Zeng Fanhui, Guo Jianchun, He Songgen. Fracture parameters optimization for tight sandstone gas reservoir horizontal well fracturing [J]. natural gas industry, 2012,11:54-58+118-119(In Chinese).

[3] Gao Haihong, Cheng Linsong, Qu Zhanqing. Fracture parameters optimization study for horizontal well fracturing [J]. Xi'an Shiyou University (Natural Science), 2006,02:29-32+4(In Chinese).

[4] Narayanan, K., White, C. D., Lake, L. W., Willis, B. J. Response Surface Methods for Upscaling Heterogeneous Geologic Models, paper SPE 51923, presented at the SPE Reservoir Simulation Symposium, Houston, Texas, USA, 14-17 February, 1999.

[5] Jirawat Chewaroungroaj, Omar J. Varela. An Evaluation of Procedures to Estimate Uncertainty in Hydrocarbon Recovery Predictions. SPE 59449, presented at the 2000 SPE Asia Pacific Conference on Integrated Modelling for AsseManagement held in Yokohama, Japan, 25-26 April 2000. 